\title{
CONSUMO E JOGOS DIGITAS NA INFÂNCIA: Uma reflexão a partir do minecraft
}

\author{
CONSUMPTION AND DIGITAL GAMES IN CHILDHOOD: A reflection from the minecraft
}

Debora Maria dos Santos. ${ }^{1}$

http://dx.doi.org/10.52641/cadcaj.v6i4.545

\begin{abstract}
RESUMO: O presente artigo consiste numa investigação acerca do consumo na infância. Para esse objetivo, será analisado o gosto das crianças por novas tecnologias, tendo como base o desenvolvimento do jogo digital Minecraft em relação a análise histórica e contextual da espontaneidade do ato de jogar. Assim, no decorrer da argumentação, a análise sobre o comportamento do consumidor e os jogos digitais destacam estratégicas lúdicas do advergaming, ou seja, uma maneira lúdica em que o próprio jogador se torna um patrocinador do seu próprio entretenimento. A constatação de que, enquanto prosumers, as crianças têm as tecnologias digitais em seu cotidiano e que tal fato é importante também como ferramenta pedagógica de aprender, nos levou a entender que a consciência do consumo é também parte da construção da criança de seu mundo virtual e real, seja no Minecraft, como também no seu processo de cidadania.
\end{abstract}

Palavras chave: consumo; infância; jogos digitais.

ABSTRACT: This article consists of an investigation into the consumption in childhood. For this purpose, will be analysed the taste of children for new technologies, based on the development of the digital game Minecraft in relation to historical and contextual analysis of the spontaneity of the Act of play. Thus, in the course of argument, the analysis of consumer behavior and digital games highlight the playful advergaming strategic, i.e., a playful way in which the player himself becomes a sponsor of your own entertainment. The finding that, while prosumers, children have digital technologies in your daily life and that this fact is important as well as pedagogical tool to learn, we understand that consumer awareness is also part of the child's construction of your virtual world and real, whether in Minecraft, as well as your citizenship process.

Keywords: consumption; childhood; digital games.

\section{Introdução}

No início da primeira década do século XXI a relação entre as crianças e a indústria do entretenimento passou por alterações substanciais ao longo do tempo, sendo atualmente conectada, e, de certa forma, menos passiva, tornando a crianças coprodutora de conteúdo. A

\footnotetext{
${ }^{1}$ Doutoranda no PPGCOM UFPE, Mestre em Consumo e Desenvolvimento Social UFRPE e Graduada em Rádio, TV e Internet pela UFPE. Bolsista Capes Demanda Social. Integrante do Grupo de Pesquisa cadastrado ao CNPQ em Publicidade Híbrida e Narrativas do Consumo (PHINC).
} 
infância atual é conectada às novas tecnologias e de acordo com o panorama apresentado pelo Comitê Gestor da Internet no Brasil em 2010, 29\% das crianças entre 5 e 9 anos já participam de alguma forma das redes sociais.

Existem algumas motivações que levam as empresas a se interessarem pela aproximação do público infantil e entre eles estão: o gosto da criança por novas tecnologias, o sucesso que fazem as redes sociais e os jogos, a facilidade de monitorar o comportamento do consumidor e a incerteza quanto ao futuro da publicidade dirigida ao público infantil em mídias tradicionais. Através dessas novas possibilidades no campo das mídias digitais, as marcas vêm se apropriando dos ambientes virtuais e conquistando através da personificação da marca, da ubiquidade e do apelo ao engajamento. (COSTA; GUEDES, 2013, p. 98).

A escolha do tema dessa pesquisa se justifica, portanto, pelos múltiplos questionamentos que permeiam o debate sobre o consumo infantil e sua relação com a indústria do entretenimento, problematizando as diversas representações contemporâneas da infância em uma sociedade em constate mudança.

O consumidor infantil já é uma parcela importante na sociedade do consumo e a participação das crianças como protagonistas no mundo dos produtos e o desejo delas em consumir fornece uma base ao atual e emergente status delas como indivíduos portadores de direito.

A indústria do entretenimento ocupa um lugar de destaque na Sociedade das marcas, deixando evidente o papel dos indivíduos como consumidores em potencial. É nesse meio que as crianças preenchem suas horas de brincadeira e tempo livre.

Nesse contexto, Schmidt (2012) afirma que não se pode deixar de considerar a indústria de entretenimento como um poderoso espaço produtor de culturas infantis onde as diversas infâncias estão sendo compreendidas e vistas como uma "lucrativa possibilidade de investimento num tempo em que o marketing infantil cresce vertiginosamente" (SCHMIDT, 2012, s.n). Vale ressaltar que a mídia, seja ela digital ou não, é cada vez mais onipresente no cotidiano dos indivíduos e sua influência pode ser observada de forma significativa na sociedade atual, o que se tornou um elemento da cultura contemporânea.

De acordo com a Pesquisa Brasileira de Mídia (PBM) 2016, metade dos brasileiros ouvidos na pesquisa $(50 \%)$ usa a internet todos os dias, sendo que no ano de 2015 , foram $37 \%$ dos entrevistados. A pesquisa mostra também que os entrevistados ficam conectados em média cinco horas por dia. Atualmente, a tecnologia está cada vez mais presente na vida de todos, através dos smartphones que integram vários serviços na palma da mão, possibilitando alto grau de interação, sendo os aplicativos de jogos os preferidos pelas crianças. 
No Brasil existem duas entidades ligadas ao mercado, a Associação Brasileira de Games (AbraGames) e a Associação Comercial, Industrial e Cultural dos Jogos Eletrônicos no Brasil (Acigames).

A pesquisa GAME BRASIL 2017, realizada pela Escola Superior de Propaganda e Marketing (ESPM) em parceria com a desenvolvedora de jogos Sioux e com a Blend New Research, o Brasil é o quarto país em número de usuários de jogos digitais, sendo cerca de 3,4 milhões de “gamers", movimentando um mercado de cerca de U\$1,5 bilhões de dólares com perspectiva de crescimento pois ainda é um mercado em expansão com muitos setores a serem explorados. Com o mercado de games em crescimento, cresce também a discussão sobre os aspectos legais e a necessidades de entidades relacionadas ao setor.

Segundo a BBC, em matéria publicada em 2015, um dos jogos ${ }^{2}$ digitais mais jogado atualmente pelas crianças se chama Minecraft. ${ }^{3}$, criado em 2009 pela Mojang, e disponível em diferentes plataformas, como Android, IOS, Xbox 360, Playstation 3, entre outros, e que tem como público alvo faixas etárias distintas. É um jogo que pode ser jogado no celular, no computador e no videogame. A sinopse oficial diz que "em um mundo 3D, onde as coisas são feitas de blocos, é preciso criar e destruir absolutamente tudo. Durante a noite, a missão é sobreviver a ataques de criaturas terríveis". O jogo é feito de blocos cúbicos que podem ser usados de diversas formas para construir estruturas no mundo virtual. O Minecraft é um jogo que pode ser explorado pelo usuário de forma autônoma, transformando o ambiente de acordo com sua vontade e estabelecendo seus próprios objetivos.

Segundo Gee (2010), vários princípios de aprendizagens podem ser relacionados a esse jogo, como o pertencimento, a descoberta, a afinidade, entre outros. Já Schuytema (2008) define o jogo eletrônico como uma atividade lúdica formada por ações e decisões que resultam numa condição final, onde são limitadas por um conjunto de regras. Já nos jogos digitais, que representam a evolução dos jogos eletrônicos, as ações e decisões são regidas por programas de computador.

\section{Uma breve história dos jogos}

Entre as atividades mais rudimentares do homem, o jogo se faz presente, e, segundo Johan Huizinga (2003), mais antigo que a própria cultura, pois pressupõe a sociedade humana, o jogo já era desenvolvido pelos animais, sem a iniciação pelo homem. Segundo o autor, é "possível afirmar com segurança que a civilização humana não acrescentou característica essencial alguma à ideia

2http://www.bbc.com/portuguese/noticias/2015/05/150518 minecraft videos viciantes rb 3https://jogos.uol.com.br/ultimas-noticias/2016/01/20/x-motivos-para-seu-filho-jogar-minecraft.htm Acessado em 06/06/16 
geral de jogo" (HUIZINGA,2003, p. 3-6). Para o autor, o jogo marcou as grandes atividades arquetípicas da sociedade humana, e destaca a linguagem como um instrumento inteiramente marcada pelo jogo, criada para poder se comunicar, ensinar e comandar.

Huizinga (2003) define o jogo como mais que um fenômeno fisiológico ou um reflexo psicológico, ele ultrapassa os limites da atividade puramente física ou biológica e assume uma função significante, que transcende as necessidades imediatas da vida e confere um sentido à ação. Para ele, todo jogo significa alguma coisa, e suas definições são divergentes quanto à função biológica, no entanto são características que tendem a se complementar, porém ainda não se aproximariam de uma verdadeira compreensão do jogo. O referido autor afirma que o jogo está em diversas esferas da vida em sociedade, desde os rituais religiosos, artes, leis, e nas interações sociais que norteiam a sociedade.

\begin{abstract}
Umas [teorias] definem as origens e fundamento do jogo em termos de descarga da energia vital superabundante, outras como satisfação de um certo "instinto de imitação", ou ainda simplesmente como uma "necessidade" de distensão. Segundo uma teoria, o jogo constitui uma preparação do jovem para as tarefas sérias que mais tarde a vida dele exigirá, segundo outra, trata-se de um exercício de autocontrole indispensável ao indivíduo. Outras vêem o princípio do jogo como um impulso inato para exercer uma certa faculdade, ou como desejo de dominar ou competir. Teorias há, ainda, que o consideram uma "ab-reação", um escape para impulsos prejudiciais, um restaurador da energia dispendida por uma atividade unilateral, ou "realização do desejo", ou uma ficção destinada a preservar o sentimento do valor pessoal, etc. (HUIZINGA,2003, p. 5).
\end{abstract}

Fazendo um contraponto da visão de Huizinga, Caillois (1990) vai contra a teoria de que todas as manifestações importantes da cultura estariam permeadas pelo jogo, e afirma que as atitudes básicas que regem os jogos (competência, sorte) nem sempre se encontram isolados, pois muitos jogos são constituídos em sua capacidade de associação. Para Caillois (1990), definir uma cultura unicamente a partir de seus jogos, seria uma operação arriscada, pois não seria possível definir sem uma análise aprofundada sobre quais e como os jogos concordam com os valores sociais. Caillois(1990) afirma que não há uma perversão do jogo e explica que os jogos sempre aparecem margeando a organização da sociedade, mas já foram vistos como parte de instituições fundamentais na antiguidade, e sua função social na atualidade se modificou com o passar dos séculos, porém sua essência continua a mesma.

Caillois (1990) argumenta que o jogo deve ser definido como uma atividade livre e voluntária, fonte de alegria e divertimento e que um jogo em que fossemos forçados a participar deixaria imediatamente de ser jogo e se tornaria uma coerção. Seria uma forma de esquecer os problemas, se afastar da vida cotidiana e se divertir, tendo sempre a possibilidade de escolher não jogar mais. 
Obrigatório ou simplesmente recomendado, o jogo perderia o jogo uma de suas características fundamentais, o facto de o jogador a ele se entregar espontaneamente, de livre vontade e por exclusivo prazer, tendo a cada instante a possibilidade de optar pelo retiro, pelo silêncio, pelo recolhimento, pela solidão ociosa ou por uma actividade mais fecunda. (CAILLOIS,1990, p. 26)

Do ponto de vista pedagógico, Silveira e Cunha (2014) definem o jogo como um lugar de construção de uma cultura lúdica, que desempenha papel fundamental no processo de socialização das crianças onde, através do brincar, ela desenvolve um autoconhecimento e amplia sua visão em relação ao mundo. Por meio do jogo, as crianças exercitam sua autonomia e sua sociabilidade, representando a sua realidade e o cotidiano que ela está inserida.

Já do ponto de vista da comunicação. McLuhan (1964), em sua obra clássica, Os meios de comunicação com extensão do homem, afirma que:

Os jogos são artes populares, reações coletivas e sociais às principais tendências e ações de qualquer cultura. Como as instituições, os jogos são extensões do homem social e do corpo político, como as tecnologias são extensões do organismo animal. [...] Os jogos são modelos fiéis de uma cultura. Incorporam tanto a ação como a reação de populações inteiras numa única imagem dinâmica. (MCLUHAN, 1964, p.264)

Segundo Orso (1999), o jogo é fundamental para quando a criança for adulta saber lidar com "as regras do jogo da vida", como ganhar e perder, lidar com o grupo, ter um senso de justiça, valores e habilidades desenvolvidas durante os jogos e que são aprendidos de forma lúdica e divertida.

Os jogos podem ser classificados de diversas formas, sob a luz de alguns autores. Piaget (2014, p.305) interpretou a classificação de Gross e Claparède (S/d), que adotam como critério classificatório a função dos jogos infantis e os dividem em duas categorias:

Jogos das funções gerais - jogos em que se utilizam as funções cognitivas e experimentações. São jogos sensoriais (gritos), motores (corridas, bola), afetivos (sexuais), intelectuais (imaginação);

Jogos das funções especiais - jogos que se colocam como exercícios preparatórios ou que exijam uso de instinto. São jogos de luta, imitação, jogos sociais.

A partir de observação de análises já existentes, Piaget (ano) também desenvolveu uma classificação para os jogos que acompanham as fases do desenvolvimento mental infantil descritas por ele, que distribuiu os jogos em três grandes categorias:

Jogo de exercício sensório motor - Consiste em movimentos simples, como caminhar, pular, correr. Começa na fase maternal e se mantém durante toda a infância até a fase adulta; 
Jogos simbólicos - (de ficção ou imaginação e de imitação) -Aparece de forma predominante entre os 2 e 6 anos com o objetivo de transformar o real para satisfazer o eu, assimilando a realidade;

Jogo de regras - Começa a se manifestar por volta dos cinco anos e se desenvolve entre os sete e os doze anos de idade. São jogos que se caracterizam por ter um conjunto de regras impostas pelo grupo, tem caráter de representação social. Esses jogos continuam durante toda a vida (esportes, jogos de xadrez, RPG...).

Como forma de complementar o que já foi citado por Piaget, Max Haetinger e Daniela Haetinger (2009) classificam outras modalidades usadas comumente como recursos pedagógicos:

Jogos artísticos - que se utilizam de elementos das artes plásticas, teatrais e musicais;

Jogos expressivos - atividades que envolvem expressões corporais e dança;

Jogos recreativos - livres, feitos em grupos ou individualmente, que proporcionam vivências alegres;

Jogos desportivos - que envolvem competição;

Jogos de tabuleiro - que usam do raciocínio lógico para chegar a um objetivo;

Jogos educacionais - que envolvem técnicas de aprendizado.

Jogos eletrônicos - desenvolvidos em plataformas digitais ou virtuais, como o tempo se transformaram em jogos digitais, por estar em conexão com a internet. Ex. Minecraft.

\section{Jogos Digitais e consumo}

O desenvolvimento da internet através da web possibilitou a criação de uma sociedade cada vez mais conectada, redefinindo e possibilitando novas formas de manifestações culturais. Castells (1999) considera a internet como a "espinha dorsal" das interações da sociedade contemporânea e afirma que ela traz importantes implicações para nossa vida social e cultural, transformando o tempo e o espaço, dimensões fundamentais para a humanidade. Essas transformações também interferem na maneira de ver e entender a infância e suas instâncias na sociedade em rede. Para Colusi e Firmino (2016), essas manifestações culturais alteram a produção da indústria do entretenimento e dos meios de comunicação, adaptando os produtos culturais a audiências cada vez mais segmentadas. 
Segundo levantamento feito pelo Serviço Brasileiro de Apoio às Micro e Pequenas Empresas (SEBRAE, 2012), o Brasil possui mais de 45 milhões de jogadores, sendo o quarto país do mundo em números de consumidores. A Super Data Research (2013) afirma que o Brasil corresponde a 62\% do mercado da América Latina.

De acordo com Menezes (2015), o sucesso dos jogos eletrônicos no Brasil e na America Latina se dá também pela diversidade das plataformas que eles são desenvolvidos, se dividindo em jogos para consoles, para computador (PC), online e para mobile (iOS, tablet, android, smartphone). A autora afirma que os jogos para console e PC já constituem um mercado maduro e estão diminuindo suas vendas, enquanto que os jogos online em aparelhos móveis estão no auge das vendas no mercado.

É cada vez maior a utilização de jogos digitais por crianças, no entanto, ainda é uma realidade nova que oferece novos desafios para as instituições encarregadas da proteção integral de crianças e adolescentes. Segundo Ferraris (2008), os jogos eletrônicos desempenham um papel de destaque na vida das crianças, pois introduzem, de forma lúdica, noções de norma, fazendo com que a criança perceba a importância de seguir regras pré-estabelecidas para cada tipo de jogo.

Para Provenzo Jr (2004), os jogos eletrônicos representam uma forma complexa e rapidamente envolvente a que muitos pais/adultos dão pouca atenção. Ele destaca que as tecnologias cada vez mais sofisticadas e mais realistas e interativas refletem o significado que a tecnologia tem na infância contemporânea.

\footnotetext{
Alguns analistas estimaram que até o final do século os programas de diversão interativa poderão ser uma indústria de 35 bilhões de dólares. Muito desta indústria envolverá os tipos de jogos baseados em tecnologia participativa descritos acima. $\mathrm{O}$ maior público alvo será sem dúvida as crianças. (PROVENZO JR, 2004, p. 166)
}

A indústria dos jogos eletrônicos trabalha com empenho para manter a criança fiel ao seu produto e a publicidade alimenta o desejo por consumir e viver a experiência que determinados produtos oferecem. Provenzo Jr (2004) alertou para uma mudança que estava ocorrendo na indústria do entretenimento. Inicialmente, na década de 1990 era comum os jogos eletrônicos serem adaptações de filmes de sucesso, porém com o passar dos anos, os videogames ganham mais importância comercial e em consequência mais de narrativa, invertendo essa ordem. Atualmente, a indústria do cinema e dos jogos eletrônicos se retroalimenta, porém caminham de forma autônoma. $O$ autor levanta um questionamento interessante e ainda pertinente: 
que os envolvem e são transferidas para o mundo cinematográfico são igualmente violentas? (PROVENZO JR, 2004, p. 16)

Através de narrativas que envolvem som e imagem, reais ou não, os jogos digitais promovem uma experiência de imersão por meio desses recursos, proporcionando aos jogadores possibilidades diversas, como construir um personagem, ou vivenciar aventuras impossíveis no mundo real, ações que ultrapassam a barreira da realidade.

Para manter esse mercado são criadas várias estratégias para captar a atenção do consumidor, seja com a promessa de um novo produto a ser lançado ou com subprodutos como livros, brinquedos e roupas. Isso leva o indivíduo a uma busca incessante pelo consumo de bens que logo a seguir serão substituídos pelas novidades do momento, tornando tudo descartável. Retornando a Huizinga e em consonância com os atuais estudos da construção da cultura infantil

O jogo é mais do que um fenômeno fisiológico ou um reflexo psicológico. Ultrapassa os limites da atividade puramente física ou biológica. É uma função significante, isto é, encerra um determinado sentido. No jogo existe alguma coisa 'em jogo' que transcende as necessidades imediatas da vida e confere um sentido à ação. Todo o jogo significa alguma coisa (HUIZINGA, 2001, p. 4).

Segundo Solomon (2016) nos estudos sobre o comportamento do consumidor, cerca de três quartos dos consumidores americanos jogam videogames, o que serve de estímulo para muitas empresas integrarem suas marcas aos jogos, fazendo um tipo de publicidade chamada de advergaming $\left(\right.$ advertising + game $\left.^{4}\right)$ para atingir grupos específicos de consumidores. Segundo o autor, esta estratégia está crescendo no mercado e funciona tanto como uma espécie de outdoor ou um entretenimento patrocinado, integrando a marca diretamente ao jogo. (SOLOMON, 2016)

Os jogos digitais já desempenham um papel significativo na vida das crianças, e, por conta disso, Ferraris (2008) considera que são várias as características associadas a esta atividade, entre elas a integração de diversas conotações simbólicas, dinamismo, criando imagens e efeitos muito próximos à realidade, interação, sensação de domínio, construindo o cenário e projetando alterações, participação construtiva, rupturas da linearidade, favorecendo novas formas de aprendizagem e promovem a conectividade através de redes sociais. A indústria de jogos eletrônicos usa diversas estratégias publicitárias para atrair o consumidor infantil, que vai desde anúncio em revistas, franquia de filmes e até canais no Youtube ensinando a melhor forma de jogar. De acordo com Levin (2007), o ritmo frenético dos lançamentos dos novos jogos afeta a delimitação da infância e da adolescência que tende a seguir o ritmo ditado pela indústria do entretenimento.

${ }^{4}$ Em tradução livre - publicidade em jogos.

Cadernos Cajuína, V. 6, N. 1, 2021, p. 275-289. 


\section{MINECRAFT: UMA AVENTURA EM BLOCOS}

Um dos jogos digitais mais usados atualmente pelas crianças se chama Minecraft que em tradução livre quer dizer algo como "minha construção", e tem como público-alvo faixas etárias distintas. É um jogo que pode ser jogado no celular, no computador e no videogame. A sinopse oficial diz que "em um mundo 3D, onde as coisas são feitas de blocos, é preciso criar e destruir absolutamente tudo. Durante a noite, a missão é sobreviver a ataques de criaturas terríveis. " O jogo é feito de blocos cúbicos que podem ser usados de diversas formas para construir estruturas no mundo virtual, e não especifica a faixa etária do seu público alvo. Abaixo na figura 1, estão os personagens e elementos principais do Minecraft.

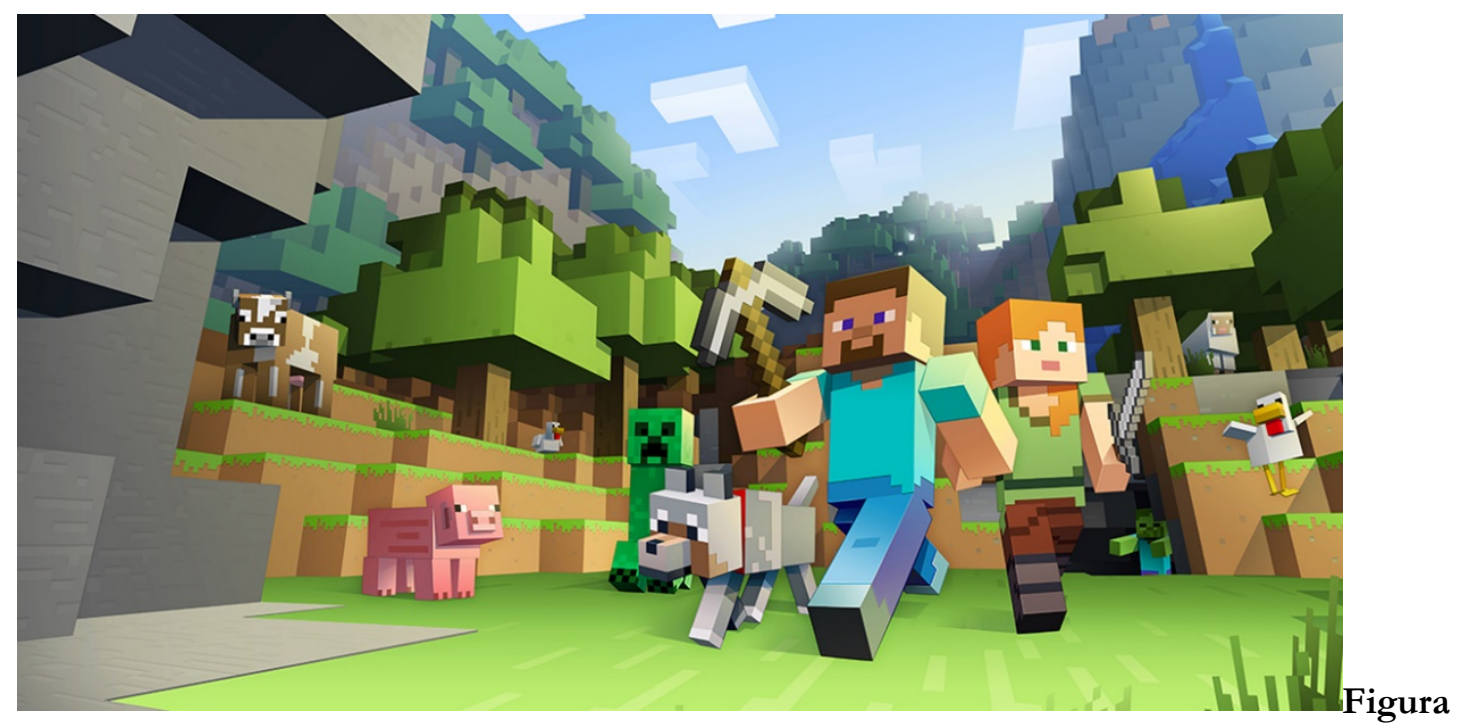

1: Mundo Minecraft - Fonte: https://minecraft.net/pt-br/store/ Acesso: 05/03/2018

A primeira versão de Minecraft foi criada na Suécia em 2009 por Markus Persson, na programação Java Language $34^{5}$ e desde o lançamento, o software é atualizado regularmente e expandido para incluir novas funcionalidades. O lançamento oficial do jogo só foi feito em 2011, em uma versão gratuita e outra Beta. De acordo como pesquisador Greg Lastowka (2011), o Minecraft teve um baixo custo que reflete no seu nível de sofisticação, além de apresentar uma estética sem muita definição, beirando a estética retrô em referência aos jogos dos anos 1990. O Minecraft teve um sucesso raro de se alcançar em jogos, e quase impossível para jogos denominados

\footnotetext{
5Java é uma linguagem de programação lançada em 1995, e é uma das linguagens de programação mais famosas do mundo, principalmente pelas aplicações Web.
}

Cadernos Cajuína, V. 6, N. 1, 2021, p. 275-289. 
"Indie." (usado para descrever jogos feitos pelos criadores solo ou pequenos estúdios). Com o dinheiro arrecadado em publicidades, em 2011 foi fundada a Mojang, empresa que atualmente desenvolve o jogo e pertence ao criador do jogo, Markus Persson.

No Minecraft não existe ganhadores, nem um enredo pré-definido, os jogadores precisam se empenhar e serem criativos para dar continuidade ao jogo. Uma vez que o jogador reuniu recursos (blocos), podem usar esses recursos na personalização de construções diversas que vão desde um poço, até uma grande obra arquitetônica, como uma barragem. O jogo é similar aos brinquedos de montar da marca Lego, que recentemente lançou um brinquedo licenciado do Minecraft, no qual é possível montar vários ambientes característicos do jogo. A figura 2 mostra a versão completa do brinquedo, que também pode ser adquirido de forma fracionada.

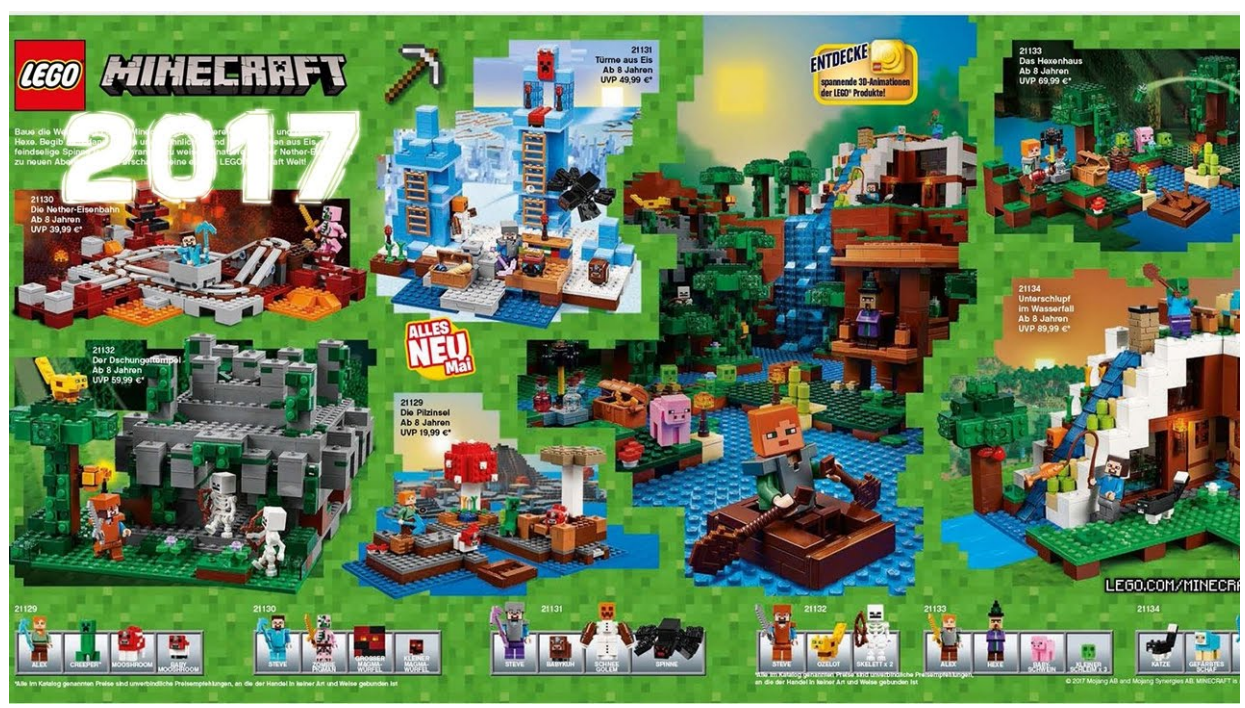

Figura 2: Imagem do brinquedo Lego -

Fonte:https://www.legobrasil.com.br/temas/minecraft\#1- Acesso: 05/03/2018

Os jogadores criam avatares (representação da pessoa, feita através de um desenho gráfico) de acordo com modelos já existentes que seguem o conceito estético do jogo, tendo cabeças e corpos em forma de blocos (figura 3). O cenário, a paisagem do jogo, também tem essa estética, sendo árvores, gramas e água compostos por blocos.

${ }^{6}$ Independente, fora do mainstream, ou seja, de uma tendência ou moda dominante. 


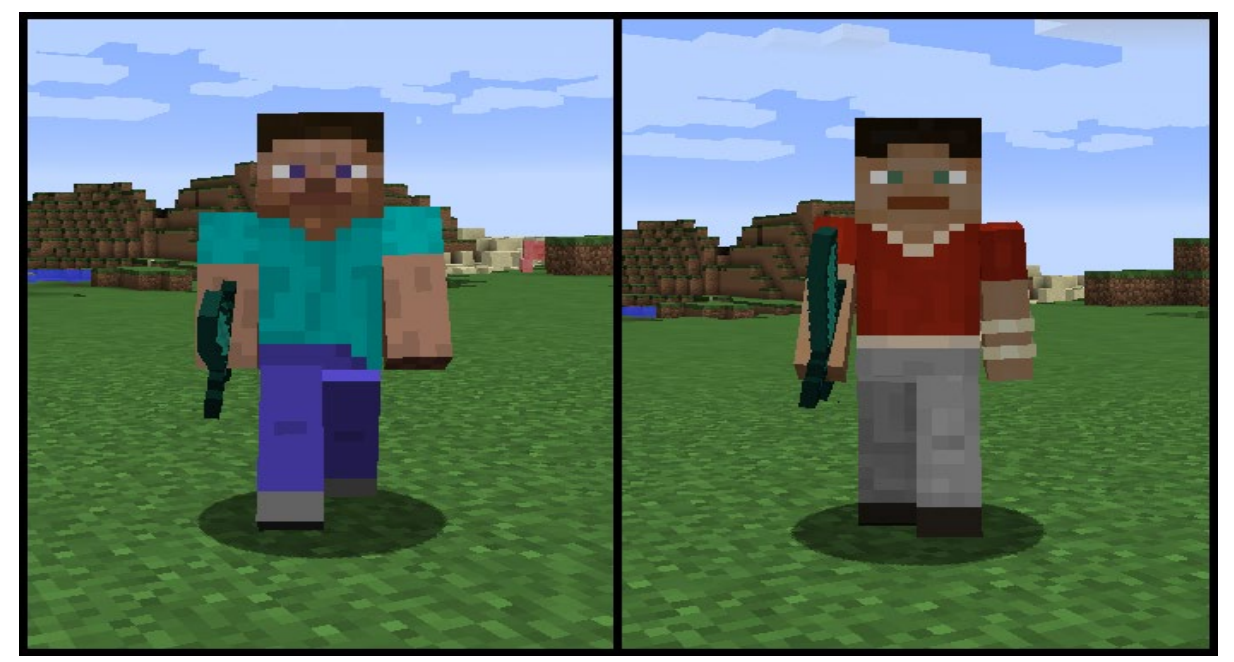

Figura 3: Avatares - Fonte: http://in.ign.com/minecraft/59983/news/minecraft-may-getoptional-new-player-models - Acesso: 05/03/2018

Através de ferramentas de captura de vídeos, os jogadores do Minecraft compartilham seus feitos na plataforma de vídeos YouTube. Atualmente, quando pesquisado o termo "Minecraft", aparecem cerca de 164 milhões de vídeos, se destacando alguns canais com milhões de visualizações. Muitos desses vídeos mostram estruturas construídas pelos jogadores e passo a passo do que tem que ser feito para fazer algo semelhante. Os canais mais curtidos no Brasil são o Authentic Games, o Rezende Evil e o VGA Minecraft. As iniciativas dos jogadores fazerem vídeos de seus feitos no jogo acaba sendo umas das principais vias de divulgação do Minecraft, transformando os usuários em prosumers ${ }^{7}$, pois ao mesmo tempo que consomem, também produzem material para a marca. Abaixo (figura 4) segue uma captura de tela do site Youtube, com o resultado da pesquisa feita através da palavra Minecraft.

${ }^{7}$ Do inglês producer and consumer, união dos papéis de produtor e consumidor, descritos pelo pesquisador Alvin Toffler em 1980. (autor, data) 


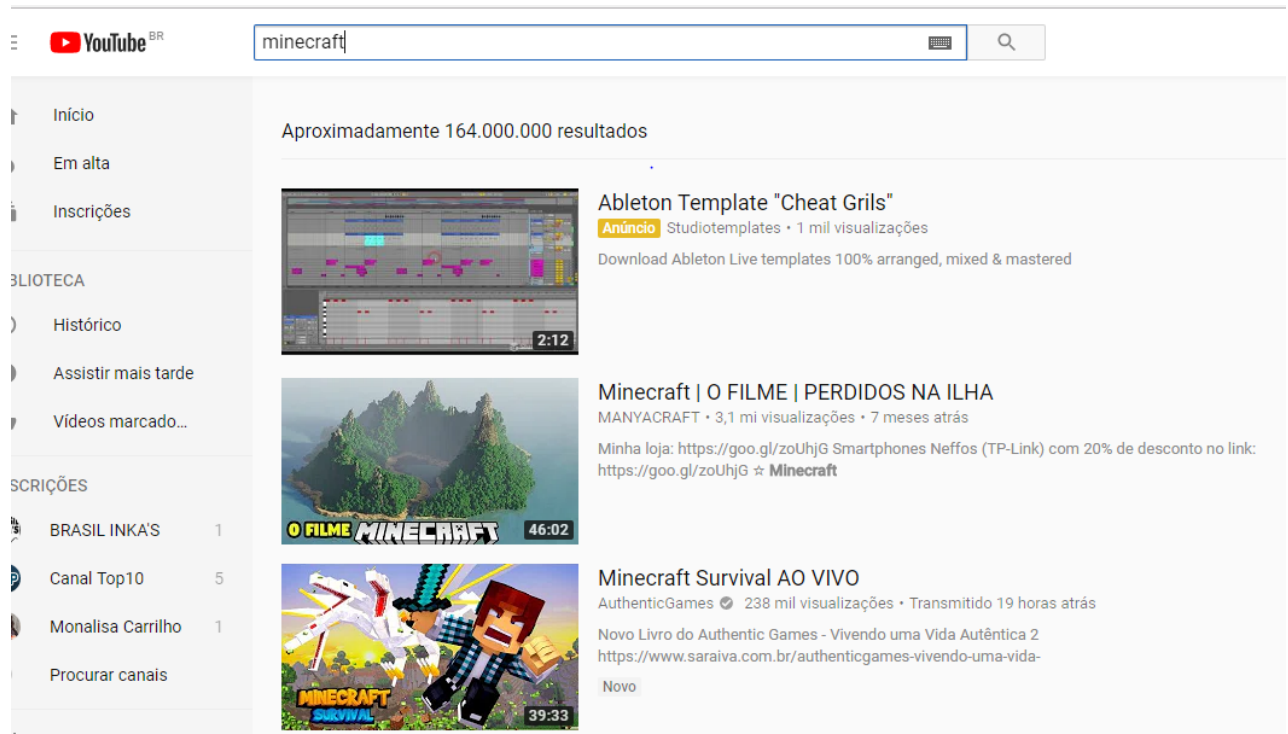

Figura 4: Print Screen feito pela autora da tela do Youtube mostrando os resultados da pesquisa do termo Minecraft - Acesso: 05/03/2018

Apelando sempre para o lado criativo, o jogo Minecraft não disponibiliza um manual para jogá-lo, incentivando a interação entre os jogadores em diversas plataformas, como redes sociais, blogs e o próprio Youtube. O jogador é incentivado através de um conteúdo amador, a iniciar seu processo criativo, tornando o jogo único. Lastowka (2011) afirma que ele não é apenas uma forma de conteúdo de mídia padrão, mas sim uma ferramenta criativa, que apresenta para os usuários uma paisagem simulada e diversas ferramentas para manipular essa paisagem, exigindo criatividade que ultrapassa os limites do jogo. Com essas características, o jogo adquire um caráter colaborativo, sem o aspecto da competição, onde a interação com outros jogadores coloca-os em um ambiente de sociabilidade, seja online ou off-line.

Segundo Gee (2010), vários princípios de aprendizagem podem ser relacionados a esse jogo, como o pertencimento, a descoberta, a afinidade, entre outros. O Minecraft é um jogo que pode ser explorado pelo usuário de forma autônoma, transformando o ambiente de acordo com sua vontade e estabelecendo seus próprios objetivos.

Ao analisarmos os conceitos que envolvem os jogos mostrados nesse capitulo, pode se observar a relação que ele tem com a brincadeira, a ludicidade, tanto no mundo digital, quanto no mundo fora das telas. A partir da relação saudável com jogos as crianças se desenvolvem, veem o mundo através de representações, aprendem a lidar com regras e a lidar com seus pares na sociedade.

\section{Conclusão}


As mudanças nas definições de infância são influenciadas pela presença marcante dos meios de comunicação, por esse motivo torna-se relevante atentar para a importância que a indústria do entretenimento exerce junto à infância contemporânea, em particular o consumismo, uma das influências mais perceptíveis dessa geração, onde os jogos eletrônicos se destacam comercialmente, principalmente pelo o uso de personagens da indústria do entretenimento como estratégia de marketing para motivar o consumo junto ao público infantil.

O consumo é um dos elementos constituintes das identidades infantis contemporâneas e está inserido no cotidiano das crianças desde muito cedo, seja em brinquedos, materiais escolares, roupas, etc., levando a um consumo cada vez maior, pois aquilo que ela possui também passa a contar no seu sentimento de pertencimento, seja na sociedade ou no ambiente escolar.

A indústria do entretenimento passou por transformações ao longo dos anos, sendo atualmente conectada, móvel e dinâmica, transformando a criança em coprodutora de conteúdo. Se há algumas décadas atrás as crianças vinham televisão em uma hora e dia determinados pelas emissoras, hoje, com plataformas como o Youtube, elas têm todo seu conteúdo sem restrição de tempo e espaço na palma da mão, se antes o sonho dourado de ser "artista" dependia de um golpe de sorte, hoje elas podem produzir seu próprio conteúdo e disponibilizar para milhares de pessoas. As novas tecnologias hoje são consideradas como um "meio", onde acontecem as interações, inovações de brincadeiras e espaço lúdico para as crianças,

A tecnologia traz para a sociedade contemporânea mudanças na forma em que se desenvolvem as noções de sociabilidade durante a infância e seus desdobramentos na vida adulta, pois os usos das novas mídias trazem novas formas de sociabilidade, estruturadas e ambientadas pelas novas formas comunicação.

As tecnologias digitais fazem parte do cotidiano das crianças, inclusive nos processos educacionais e de aprendizado, tanto que os aparelhos eletrônicos podem ser um artefato pedagógico, podendo interferir de forma direta no processo de aprendizado.

\section{Referências}

CAILLOIS, Roger. Os jogos e os homens. Lisboa: Cotovia. 1990.

CASTELLS, Manuel. A sociedade em rede. A era da informação: economia, sociedade e cultura. Vol.1. São Paulo: Paz e Terra, 1999.

CLAPARÈDE e GROSS in: GRASSI, Tania Mara. Oficinas Psicopedagógicas. $2^{\circ}$ ed. Curitiba: Ibpex, 2008. 
COLUSSI, Juliana; FIRMINO, Leonardo Magalhães - Do game a galerias dinâmicas na narrativa jornalística hipermídia. Brazilian Journalism Research - Volume 12 - Número 1, p.187, 2016.

COSTA, Sílvia Almeida, GUEDES, Brenda Lyra; Consumo, infância e marcas: estabelecendo vínculos através das redes sociais digitais. In: Patrícia Bieging e Raul Inácio Busarello. (org.).Experiências de consumo contemporâneo: pesquisas sobre mídia e convergência. 1ed. São Paulo: Pimenta Cultural, 2013, v. 1, p. 81-105.

FERRARIS, Sabrina. Comunidades virtuales lúdicas: jóvenes y videojuegos. In: URRESTI, Marcelo (org.). Ciberculturas juveniles: los jóvenes, sus prácticas y sus representaciones en la era de Internet. Buenos Aires: La Crujía, 2008, p. 205-224.

GEE, James Paul. Bons Vídeos jogos + Boa aprendizagem: coletânea de Ensaios sobre os videojogos e Aprendizagem e a Literacia. Portugal: Edições Pedágio, 2010.

HAETINGER, Max Günther; HAETINGER Daniela - Jogos, recreação e lazer, Curitiba, IESDE Brasil S.A. , 2009.

HUIZINGA, Johan. Homo Ludens: Um estudo sobre o elemento lúdico da cultura. Lisboa: Edições 70. 2003

INTERSCIENCE. Criança e Consumo. 2003. Disponível em: http://criancaeconsumo.org.br/wp-content/uploads/2014/02/Doc-09-Interscience.pdf. Acesso em: 14. jul.16.

IBGE. CENSO DEMOGRÀFICO 2010. Disponível em: https://brasilemsintese.ibge.gov.br/populacao/taxas-de-fecundidade-total.html . Acesso em: 24 de maio de 2018

LASTOWKA, Greg -Minecraft as Web 2.0: Amateur Creativity \& Digital Games - October 2011.

Disponível

em: https://ssrn.com/abstract=1939241 or http://dx.doi.org/10.2139/ssrn.1939241- Acesso em $\underline{10 / 01 / 2017 .}$

MACHADO, Ed. Vício em videogame é reconhecido como doença pela OMS - FolhaPE, 2018. Disponivel em:https://www.folhape.com.br/noticias/noticias/saude/2018/06/18/NWS, 72150,70,613,NO TICIAS,2190-VICIO-VIDEOGAME-RECONHECIDO-COMO-DOENCA-PELA-OMS.aspx Acessado em 21/06/2018

MAGALHÃES, Alfredo - Escolaridade e renda dos pais influenciam carreira dos filhos, diz IBGE, 2016, Disponível em: https://economia.uol.com.br/empregosecarreiras/noticias/redacao/2016/11/16/escolaridadedos-pais-influencia-sucesso-profissional-dos-filhos-diz-ibge.htm?cmpid=copiaecola - Acesso $10 / 03 / 17$

McLUHAN, Marshall. Os meios de comunicação como extensões do homem. Trad. Décio Pignatari. São Paulo: Cultrix, 1964. 407p. 
MENEZES, Graciela Sardo. Gamificação no contexto da experiência do usuário: estudo dos elementos de game na satisfação de desejos e necessidades subjetivas dos indivíduos. Dissertação de Mestrado. Universidade Federal de Santa Catarina, 2015

ORSO, Darci. Brincando, Brincando Se Aprende. Novo Hamburgo -Feevale, 1999

PESQUISA GAME BRASIL, 2018 - Disponível em: https://www.pesquisagamebrasil.com.br/ - Acesso em 22/06/2018

PIAGET, Jean. Seis estudos de psicologia. Rio de Janeiro: Forense Universitária, 1971.

Jean. A formação do símbolo na criança: imitação, jogo e sonho, imagem e representação. Rio de janeiro: Zahar, 1978.

Jean. Relações entre a Afetividade e a Inteligência no Desenvolvimento Mental da Criança. EditoraWak, 2014.

PROVENZO JR, Eugene F. Videogames e a emergência da mídia interativa para crianças. In STEINBERG, Shirley R., KINCHELOE, Joe L. Cultura Infantil: A construção corporativa da infância. Tradução: George E. J. Bricio. Rio de Janeiro: 2001.

SCHIMIDT, Saraí - Mídia e consumo infantil: um desafio da comunicação e educação - IX AMPED SUL, $2012 \quad-\quad$ Disponível em: http://www.ucs.br/etc/conferencias/index.php/anpedsul/9anpedsul/paper/viewFile/2318/901 Acesso 26/09/17

SCHUYTEMA, P. Design de games: uma abordagem prática. São Paulo: Cengage Learning, 2008. $447 \mathrm{p}$

SEBRAE. (2012) O panorama e a evolução do mercado de "Games" no Brasil. Boletim do serviço brasileiro de apoio às micro e pequenas empresas. Disponível em http://pt.slideshare.net/MartaCaregnato/o-panorama-e-a-evolucao-do-mercado-degames-nobrasil-sebrae. Acesso em 15 de maio de 2017.

SHAFFER, David R. Psicologia do desenvolvimento: Infância e adolescência. 6. ed. São Paulo: Cengage Learning, 2005. 627 p.

SOLOMON, Michel. O comportamento do consumidor: comprando, possuindo e sendo. Tradução: Beth Honorato - 11ed - Porto Alegre, Bookman, 2016 